Abstract S7D:4 Table 1

-Association between PCS and remission, adjusted for age and SDI

\begin{tabular}{|c|c|c|c|c|c|c|c|}
\hline & & & Crude & & & Adjusted & \\
\hline & $\begin{array}{l}\text { Mean PCS } \\
( \pm S D)\end{array}$ & B & $95 \% \mathrm{Cl}$ & $p$-value & B & $95 \% \mathrm{Cl}$ & $p$-value \\
\hline $\begin{array}{l}\text { No } \\
\text { remission }\end{array}$ & $36.0(10.9)$ & ref & & & ref & & \\
\hline $\begin{array}{l}\text { Remission } \\
\text { on therapy }\end{array}$ & $41.8(10.0)$ & 6.3 & $3.2-9.3$ & $<0.001$ & 6.2 & $3.3-9.0$ & $<0.001$ \\
\hline $\begin{array}{l}\text { Remission } \\
\text { off therapy }\end{array}$ & $44.8(10.4)$ & 8.2 & $5.3-11.2$ & $<0.001$ & 8.3 & $5.4-11.1$ & $<0.001$ \\
\hline
\end{tabular}

-Association between MCS and remission, adjusted for ethnicity

\begin{tabular}{|c|c|c|c|c|c|c|c|}
\hline & & & Crude & & & Adjusted & \\
\hline & $\begin{array}{l}\text { Mean MCS } \\
( \pm S D)\end{array}$ & B & $95 \% \mathrm{Cl}$ & p-value & B & $95 \% \mathrm{Cl}$ & $\begin{array}{l}\text { p- } \\
\text { value }\end{array}$ \\
\hline No remission & $46.1(10.6)$ & Ref. & & & Ref. & & \\
\hline $\begin{array}{l}\text { Remission on } \\
\text { therapy }\end{array}$ & $49.3(10.5)$ & 2.9 & $0.1-5.7$ & 0.041 & 2.3 & $-0.5-5.1$ & 0.112 \\
\hline $\begin{array}{l}\text { Remission off } \\
\text { therapy }\end{array}$ & $46.8(10.1)$ & 0.8 & $-1.7-3.4$ & 0.52 & 0.4 & $-2.1-3.03$ & 0.739 \\
\hline
\end{tabular}

conditions. The phase represents a demanding existential situation. Support through the diagnostic phase, by considering the patient's existential challenge and incorporate this in rehabilitation programmes would emancipate patients through a demanding time and be a novel contribution to patient support.

\section{S7D:6 GOING VIRAL IN RHEUMATOLOGY: A RAPID, COST- EFFECTIVE METHOD OF OBTAINING PATIENT OPINION ABOUT RESEARCH IN SLE AND APS}

T McDonnell, C Wincup, A Rahman, I Giles. University College London, UK

\subsection{6/lupus-2018-abstract.48}

Purpose It is important to access opinions from patients in designing research into systemic lupus erythematous (SLE) and/or antiphospholipid syndrome (APS). It is difficult to obtain useful information from large numbers of unselected patients in a short period of time. There is a lack of published research about how to achieve this objective. On-line surveys and use of social media offer a potential method to address this challenge. We developed a novel approach to access patient opinion regarding key objectives for mechanistic research in SLE and APS.

Methods We developed a one-page lay summary of a research project concerning investigation of serine proteases in patients with APS and SLE. This is a mechanistic laboratory project with potential future relevance to management of these diseases. Both the lay summary and an accompanying 9-question survey were refined with the help of an expert patient and patients' charities, then disseminated as an online survey. The survey was open for four weeks, and was publicised via social media (Twitter, Facebook) and through the websites of LUPUS UK and APS Support UK. The survey data were then analysed and total project cost was $£ 26$.

Results Of 527 respondents, 520 confirmed having been diagnosed with SLE and/or APS. The majority of respondents were very positive about the research, expressing strong interest in its mechanistic basis. We provided a free text box for respondents to express their opinions about the most important research topics in SLE and APS. 277 respondents 


\section{Subjects Listed by Mentions in Patient Responses}

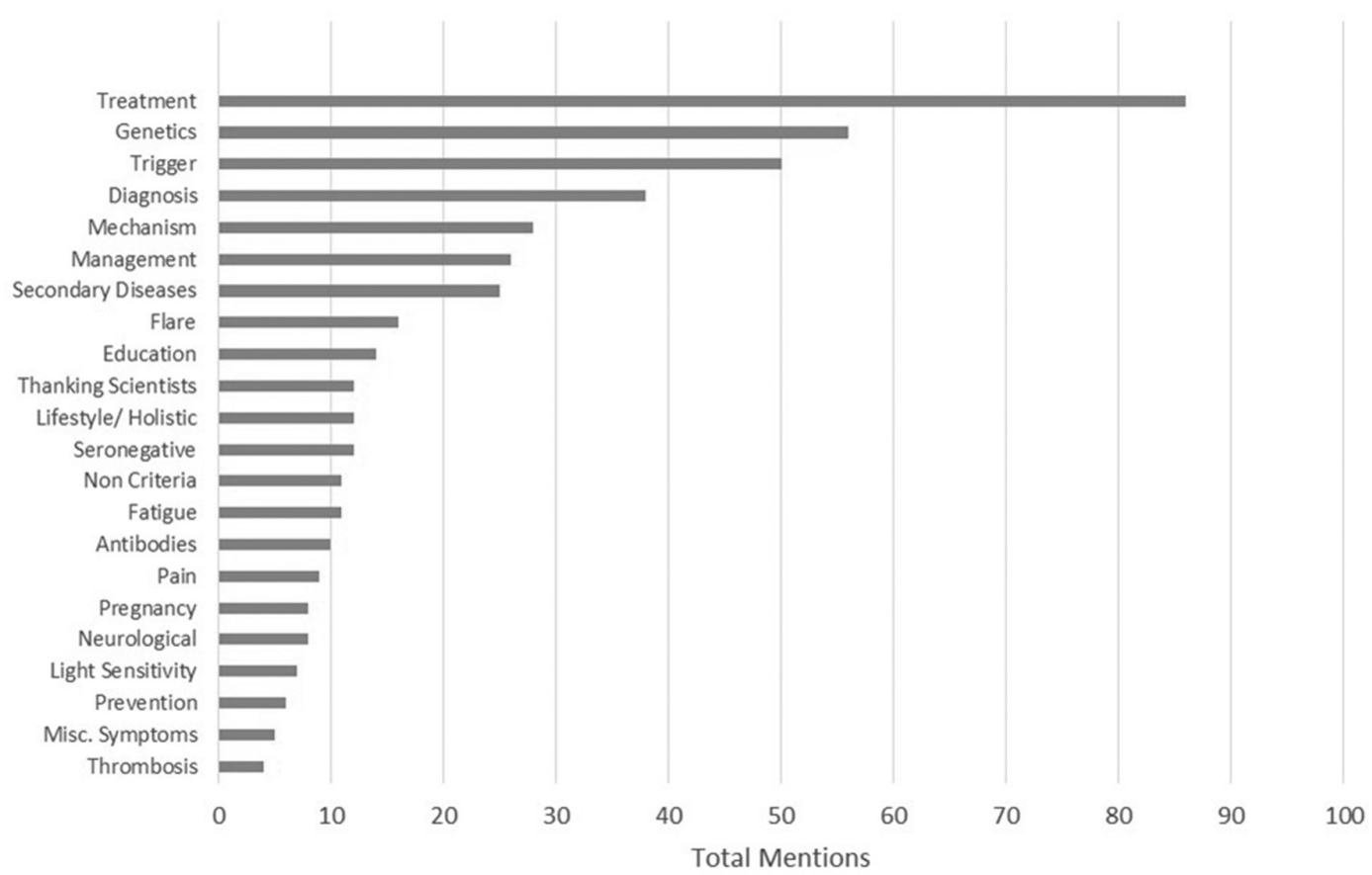

Abstract S7D:6 Figure 1 Patients responses grouped for subject matter, this demonstrates the most mentioned and least mentioned research topics

provided free text comments. The most popular research topics were Treatment (mentioned by $\mathrm{n}=86$ respondents), Genetics $(n=56)$, Triggers $(n=50)$, Diagnosis $(n=38)$ and Mechanistic Research $(n=28)$. Interestingly, patients expressed more interest in disease mechanisms than in clinical topics such as management of disease flares.

Conclusions It is possible to conduct short term, valuable patient engagement at low cost, using an online survey and social media. This methodology may form a good template for future patient engagement. Our results suggest that patients are interested in mechanistic research.

\section{S7D:7 IDENTIFYING THE LINKS BETWEEN FUNCTIONAL IRON DEFICIENCY AND FATIGUE IN SYSTEMIC LUPUS ERYTHEMATOSUS}

${ }^{1} \mathrm{C}$ Wincup, ${ }^{1} \mathrm{C}$ Parnell, 'S Cleanthous, ${ }^{2} \mathrm{~S}$ O'Neill, ${ }^{2} \mathrm{M}$ Nguyen, ${ }^{3} \mathrm{~T}$ Richards, ${ }^{1} \mathrm{~A}$ Rahman. ${ }^{1}$ Department of Rheumatology, University College London, UK; ${ }^{2}$ Department of Rheumatology, University of New South Wales, Sydney, Australia; ${ }^{3}$ Centre for CardioVascular and Interventional Research (CAVIAR), Division of Surgery, University College London, UK

\subsection{6/lupus-2018-abstract.49}

Background $80 \%-90 \%$ of patients with SLE report fatigue to be the single most debilitating symptom of their disease. Functional Iron Deficiency (FID), a state of inefficient iron utilisation, has recently been linked with fatigue in a number of conditions. Red Blood Cell Distribution Width (RDW) is a convenient marker of FID.

Purpose To study the relationship between FID (as measured by RDW) and fatigue in patients with SLE.

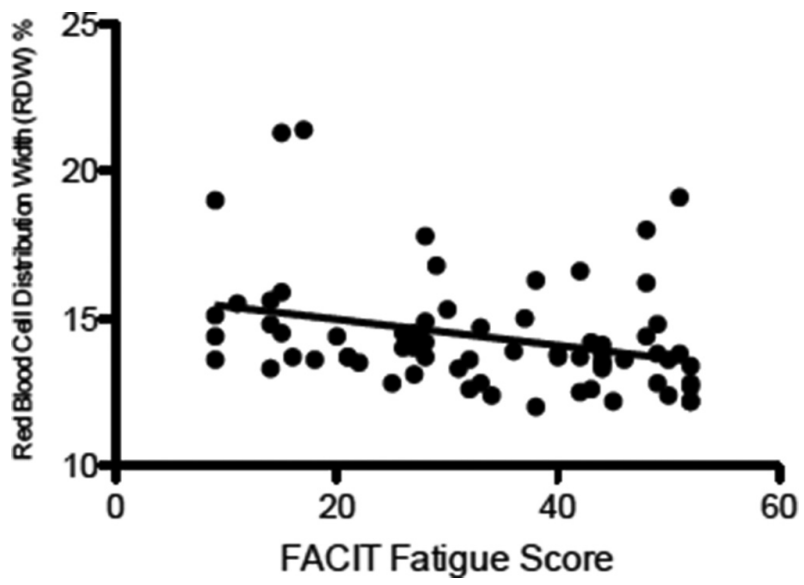

Abstract S7D:7 Figure 1 FACIT fatigue score and RDW in adolescents and young adults with SLE (UCLH cohort)

Methods Three cohorts were recruited and all patients were required to fulfil ACR criteria of lupus.

1. Juvenile-onset SLE Cohort at University College London Hospital (UCLH), London (UK)

2. Adult Cohort at UCLH, London (UK)

3. Adult Cohort at Liverpool Hospital, Sydney (Australia)

In cohorts 1 and 3, patients completed the FACIT Fatigue Score. This generates a numerical score (between 0-52), where a lower score represents more fatigue. In cohort 2, fatigue was measured using the SLE-specific quality of life index, LUPUS QoL. 